\title{
PROFESSOR DO ATENDIMENTO EDUCACIONAL ESPECIALIZADO NA ESCOLA COMUM E AS PRÁTICAS METODOLÓGICAS INCLUSIVAS
}

\author{
PROFESOR DE SERVICIO EDUCATIVO ESPECIALIZADO EN LA ESCUELA \\ COMÚN Y PRÁCTICAS METODOLÓGICAS INCLUSIVAS
}

\author{
TEACHER OF EDUCATIONAL SERVICE SPECIALIZED IN THE COMMON \\ SCHOOL AND INCLUSIVE METHODOLOGICAL PRACTICES
}

\author{
Mayara FERREIRA DE SOUZA ${ }^{1}$ \\ Mirlene Ferreira Macedo DAMÁZIO²
}

RESUMO: Perante contextos de algumas escolas, é preciso expor a transversalidade do professor do Atendimento Educacional Especializado (AEE) e as conexões necessárias na perspectiva inclusiva para garantir a inclusão e o ensino/aprendizagem dos alunos público-alvo da Educação Especial. A escola e a Política Nacional de Educação Especial na Perspectiva Inclusiva ressaltam a necessidade dessas conexões. Assim, este estudo se constitui em uma pesquisa bibliográfica com o objetivo prático de contribuir com professores do AEE, demonstrando ações do serviço para a inclusão e promoção dos alunos público-alvo com equidade e qualidade no desenvolvimento e processo de ensino/aprendizagem. Vimos que a formação do professor em uma perspectiva inclusiva e a transversalidade do serviço no todo da escola, com a organização de doze ações em favor dessa perspectiva, são apontados para garantir a acessibilidade comunicacional e pedagógica.

PALAVRAS-CHAVE: Professor. Atendimento educacional especializado. Inclusão.

RESUMEN: En el contexto de algunas escuelas, es necesario exponer la transversalidad del maestro de Asistencia Educativa Especializada (ESA) y las conexiones necesarias en la perspectiva inclusiva para garantizar la inclusión y enseñanza / aprendizaje del público objetivo de Educación Especial. La escuela y la Política Nacional de Educación Especial en la Perspectiva Inclusiva subrayan la necesidad de estas conexiones. Por lo tanto, este estudio es una investigación bibliográfica con el objetivo práctico de contribuir con los docentes de la ESA, demostrando acciones del servicio para la inclusión y promoción de estudiantes objetivo con equidad y calidad en el proceso de desarrollo y enseñanza / aprendizaje. Hemos visto que la formación del profesorado en una perspectiva inclusiva y la transversalidad del servicio en toda la escuela, con la organización de doce acciones a favor de esta perspectiva, tienen por objeto garantizar la accesibilidad comunicativa y pedagógica.

\footnotetext{
${ }^{1}$ Universidade Federal da Grande Dourados (UFGD), Dourados - MS - Brasil. Especialista em Educação Especial. Pesquisa Passo a Passo. E-mail: mayara_bbd@ @otmail.com

${ }^{2}$ Universidade Federal da Grande Dourados (UFGD), Dourados - MS - Brasil. Doutora. Professora da Faculdade de Educação da UFGD. Pesquisa Passo a Passo. ORCID: http://orcid.org/0000-0001744492261.E-mail: psmirlenefm@gmail.com
} 
PALABRAS CLAVE: Profesor. Servicio educativo especializado. Inclusión.

ABSTRACT: In the context of some schools, it is necessary to expose the transversality of the teacher of Specialized Educational Attendance (ESA) and the necessary connections in the inclusive perspective to ensure the inclusion and teaching / learning of special education target students. The school and the National Policy for Special Education in the Inclusive Perspective underscore the need for these connections. Thus, this study is a bibliographic research with the practical objective of contributing with teachers of the ESA, demonstrating actions of the service for the inclusion and promotion of target students with equity and quality in the development and teaching / learning process. We have seen that teacher education in an inclusive perspective and the transversality of service throughout the school, with the organization of twelve actions in favor of this perspective, are aimed at ensuring communicational and pedagogical accessibility.

KEYWORDS: Professor. Specialized educational service. Inclusion.

\section{Introdução}

A escola defende a Educação Inclusiva e compreende que esta faz referência a uma escola que atende as especificidades de todos os perfis de alunos, independentemente de suas condições físicas, sociais, econômicas ou capacidade. Por outro lado, nos espaços escolares percebemos equívocos que não beneficiam a perspectiva inclusiva. Em meio a isso, a Educação Especial é afetada e necessita, com urgência, de clareza em sua interpretação.

Os equívocos partem da compreensão de conceitos básicos, como o de que a educação inclusiva se refere a todos e que a educação especial é voltada para os alunos com deficiência, transtornos globais do desenvolvimento e altas habilidades ou superdotação. Portanto, a educação especial deve acontecer na perspectiva inclusiva, mas a educação inclusiva abarca a inclusão de todos da escola, e não apenas a dos alunos público-alvo da educação especial.

Outro equívoco está na implementação do serviço do atendimento educacional especializado (AEE), os decretos, leis e políticas regulamentam um serviço na perspectiva inclusiva, no entanto a interpretação dos textos tem sido prejudicada por ações da integração. Compreende-se que o movimento para que a educação aconteça na perspectiva inclusiva exige formação e que os profissionais envolvidos estejam abertos a construir e descontruir valores e conceitos estabelecidos pela história da sociedade. 
Eis que agora é necessário um olhar mais apurado diante da realidade, ações pontuais para que a perspectiva inclusiva seja potencializada e, fazendo um recorte para a educação especial, as ações pontuais precisam maximizar a aprendizagem e o desenvolvimento de seu público-alvo. Não é o momento de dizer que não funciona, mas sim de corrigir os equívocos implementados.

Assim, neste artigo propomo-nos a esclarecer algumas ações do AEE, realizadas na escola de ensino regular pelo professor do atendimento educacional especializado, a fim de contribuir com ações práticas a este profissional em benefício de seu serviço. Equivocadamente, encontramos o serviço do AEE muitas vezes com ações segregadas na Sala de Recurso Multifuncional (SRM), e suas ações não estão transversalizando o todo da escola, não há um diálogo entre o professor da sala de aula comum e o professor do AEE, e é na sala de aula comum onde se encontram os maiores entraves, tanto metodológicos e pedagógicos quanto atitudinais, para que essa efetiva educação inclusiva aconteça, mas é também o espaço mais importante para acontecer.

No entanto, como abandonar as paredes da SRM e buscar transversalizar o todo da escola? Conhecer e compreender o que as leis, decretos e políticas regulamentam acerca do serviço é o primeiro passo. O segundo seria estabelecer uma metodologia para o serviço na perspectiva inclusiva. Para isso, buscamos a literatura científica, envolvendo artigos, monografias e dissertações e teses de doutorado a partir de 2008 até os dias de hoje, destacando 18 estudos para elucidar ações que venham ao encontro de práticas metodológicas inclusivas para o professor do AEE.

\section{Os vários estudos}

Compreendendo a necessidade de debruçar nos documentos norteadores da Educação Especial, partimos da Lei Brasileira de Diretrizes e Bases da Educação Nacional (LDB) que em seu art. 58 discorre: “[...] Entende-se por educação especial, [...] a modalidade de educação escolar oferecida preferencialmente na rede regular de ensino, para educandos com deficiência, transtornos globais do desenvolvimento e altas habilidades ou superdotação" (BRASIL, 1996, p. 23), e garante os serviços de apoio especializados necessários para atender as peculiaridades do público-alvo.

Os serviços oferecidos são denominados Atendimento Educacional Especializado, e, de acordo com o Decreto 7.611, de 17 de novembro de 2011, “[...] compreendido como o conjunto de atividades, recursos de acessibilidade e pedagógicos 
organizados institucional e continuamente [...]" (BRASIL, 2011, p. 5), é complementar e/ou suplementar, e não substitutivo ao ensino regular.

No art. 3. ${ }^{\circ}$ do Decreto 7.611/2011 são apresentados quatro objetivos do AEE cujos professores precisam conhecer e fomentar as conexões necessárias para que os alunos público-alvo da Educação Especial possam estar incluídos de maneira efetiva no ambiente escolar:

I - prover condições de acesso, participação e aprendizagem no ensino regular e garantir serviços de apoio especializados de acordo com as necessidades individuais dos estudantes; II - garantir a transversalidade das ações da educação especial no ensino regular; III - fomentar o desenvolvimento de recursos didáticos e pedagógicos que eliminem as barreiras no processo de ensino e aprendizagem; e IV - assegurar condições para a continuidade de estudos nos demais níveis, etapas e modalidades de ensino (BRASIL, 2011, p. 5).

Observamos que esses documentos apresentam a transversalidade que o serviço traz e que o professor do AEE precisa articular. Buscando como organizar melhor esse ambiente inclusivo, em 2008, foi entregue ao Ministro da Educação um documento denominado Política Nacional de Educação Especial na Perspectiva da Educação Inclusiva (PNEEPEI), ressaltando e esclarecendo aspectos importantes do AEE, um serviço que:

[...] tem como função identificar, elaborar e organizar os recursos pedagógicos e de acessibilidade que eliminem as barreiras para a plena participação dos alunos, considerando suas necessidades específicas. As atividades desenvolvidas no atendimento educacional especializado diferenciam-se daquelas realizadas na sala de aula comum, não sendo substitutivas à escolarização. Esse atendimento complementa suplementa a formação dos alunos com vistas à autonomia e independência na escola e fora dela (PNEEPEI, 2008, p. $15)$.

Alves e Guareschi (2011) apontam que, na escola, o professor especialista do AEE é aquele que precisará fazer articulação para garantir movimentos que proporcionem a inclusão dos alunos público-alvo da educação especial:

Além de organizar o atendimento na Sala de Recursos Multifuncionais, o professor deverá orientar os demais colegas do ensino regular que trabalham com os alunos que frequentam o AEE. Deverá, também, nortear e acompanhar os recursos pedagógicos e de acessibilidade utilizados pelo aluno nos demais espaços escolares (ALVES; GUARESCHI, 2011, p. 41). 
Além disso, os referidos autores afirmam que o profissional do AEE precisa buscar os demais profissionais que atendem a esse aluno, como psicólogo, fisioterapeuta, fonoaudiólogo, pois "É a partir da avaliação da aprendizagem, da história familiar e escolar e da interlocução com outros profissionais [...] verificará aquilo que ele, aluno, já construiu em termos de aprendizado em todas essas esferas" (ALVES; GUARESCHI, 2011, p. 41).

Por meio de olhares diferenciados, que enxergam o sujeito em suas habilidades e capacidades, o professor do AEE conseguirá desenvolver sua função com sucesso. Entretanto, não é fácil tornar-se esse profissional versátil, e as dificuldades encontradas no contexto escolar são muitas, desde questões físicas e pedagógicas até questões atitudinais dos colegas. Logo, é necessário conhecer realidades possíveis, bem como pesquisas de estudiosos que apontam caminhos. Nos estudos realizados, percebemos que a complexidade da educação especial na perspectiva da educação inclusiva é presente em todas as leituras efetuadas e, ao mesmo tempo, os caminhos apontados são congruentes.

Algumas obras divergem-se sutilmente na compreensão da educação inclusiva como responsabilidade do professor do AEE; em outros estudos, esse profissional é apontado como colaborador no desenvolvimento de ações, dentro da escola, na perspectiva inclusiva.

O estudo "Compreendendo o Atendimento Educacional Especializado (AEE)", de Marcia Doralina Alves e Tais Guareschi, publicado em 2011, descreve as atribuições do professor do AEE, enaltece a singularidade do público-alvo da Educação Especial e destaca a formação desse profissional como elemento-chave para o bom desempenho do serviço. Aponta que o professor do AEE precisa desenvolver suas ações na perspectiva inclusiva e estabelecer assessorias aos professores e alunos na sala de aula comum, tendo um olhar diferenciado para esses sujeitos, que possuem inúmeras possibilidades.

Nos estudos Tecnologia Assistiva - TA: aplicações na educação, de Rita Bersch e Rosângela Machado; Atendimento educacional especializado para pessoas com deficiência física, de Amaral Holanda T. Battistel; "A escola como um espaço de respeito à diferença”, de Eliana da Costa Pereira de Menezes, Renata Corcini Carvalo Canabarro e Maria Alcione Munhoz, são apresentados reflexões importantes sobre a educação inclusiva, documentos e movimentos que nortearam essa perspectiva. Os autores indicam avanços, como o acesso de todos à educação, e questionam a escola, 
que ainda desempenha suas funções numa perspectiva tradicional, considerando seu público homogêneo. Ressaltam a importância de repensar as práticas da escola.

Clarificam que a educação inclusiva não se refere apenas aos alunos da Educação Especial, mas, sim, abrange todos. Destacam a importância de parceria entre todos os envolvidos para a inclusão dos alunos público-alvo da Educação Especial e apontam o professor do AEE como aquele que realiza o movimento para que essas parcerias entre pais, professores e profissionais clínicos sejam estabelecidas de maneira que o aluno seja beneficiado. Reforçam a seriedade da formação do professor do AEE para que este tenha condições de lidar com todas as demandas do serviço, pois nem sempre este deverá se restringir ao aluno.

O estudo Atendimento Educacional Especializado, de Marquezine, Tanaka e Busto, publicado em 2013, discorre sobre os principais marcos históricos para se chegar à educação especial na perspectiva da educação inclusiva, suas atribuições e como o serviço do AEE precisaria se estabelecer. As autoras apresentam algumas pesquisas para explicar como tem sido realizada a implantação do serviço nas escolas. Preocupam-se ao observar que a SRM pode negligenciar a perspectiva inclusiva, quando é vista como local exclusivo para que o AEE aconteça, pois, nessa visão equivocada, o professor do AEE realiza ações segregadas e de integração e não faz as conexões e assessorias necessárias com a sala de aula comum e com os demais envolvidos para o sucesso do aluno. Com isso, destacam a importância da organização adequada do serviço, que deve estar articulado com o ensino comum, e, além de criar parcerias com segmentos que contemplem a educação, o investimento na formação dos professores também é ressaltado.

Os estudos "Grupo de suporte aos pais e apoio pedagógico aos professores da rede e alunos com necessidades educacionais especiais na educação inclusiva”, de Carina de Souza Cantarelli; e "A rede de apoio permeando ao trabalho do professor no processo de inclusão", de Vanessa Caroline da Silva, Mônica Cecilia Gonçalves Condessa-Franke e Laura Ceretta Moreira, publicados ambos em 2013, descrevem a importância de redes de apoio entre os professores, familiares e profissionais que atendem os alunos público-alvo da Educação Especial.

Afirmam que, tratando-se de educação inclusiva, não existem receitas prontas e que o trabalho colaborativo é um caminho que enriquece as ações, potencializando o sucesso da sala de aula comum e o desenvolvimento do aluno. Citam a formação como requisito fundamental não apenas para os professores do $\mathrm{AEE}$, mas para todos da 
escola, e que a educação inclusiva não é uma tarefa fácil, mas que as escolas precisam rever suas concepções e organizar seus currículos dentro da perspectiva inclusiva, estando tudo isso clarificado nos Projetos Políticos Pedagógicos.

Exemplificando essa perspectiva inclusiva, o estudo "A importância do AEE e a mediação do professor na inclusão do aluno com deficiência intelectual na escola", de Maria Jusciene de Oliveira Silva, Jozenice Fernanda de Paiva Oliveira e Ana Lúcia Oliveira Aguiar, publicado em 2014, relata um caso em que o serviço do AEE é implantado de maneira adequada, articulado com todos os segmentos da escola, bem como com a família e outros profissionais envolvidos no desenvolvimento do aluno. Descrevem uma escola em que as ações do serviço AEE e as concepções de educação inclusiva estão presentes no Projeto Político Pedagógico (PPP) da instituição, e que a transversalidade do serviço, de forma colaborativa, garantiu que o aluno se formasse como cidadão ativo na sociedade. Contudo, para que isso ocorresse, a escola precisou rever suas práticas e considerar a heterogeneidade de seu público.

Já no estudo “Articulação entre o Atendimento Educacional Especializado e o ensino comum: construindo sistemas educacionais inclusivos", de Theresinha Guimarães Miranda, publicado em 2015, a autora parece, a princípio, compreender que o professor do AEE é responsável por tornar a escola inclusiva, mas deixa mais clara essa visão durante o texto, quando esclarece que o professor do AEE é responsável pelo público-alvo da Educação Especial.

É nesse texto que a complexidade de estabelecer a Educação Especial na Perspectiva da Educação Inclusiva passa a ser abordada e justificada por questões corriqueiras que aparecem nos demais textos, por exemplo, a inexistência de articulação entre o professor do AEE e o professor da sala de aula comum, dificultada pela falta de horário para que esses dois grupos de docentes dialoguem, e a demanda de trabalho do serviço também é apontada como empecilho, pois não sobra tempo para o professor do AEE estabelecer essas conexões com o professor da sala de aula comum. Todavia, as autoras apontam a seriedade com que os professores do AEE compreendem suas funções no serviço, existindo muitas vezes o sentimento de solidão, que o trabalho colaborativo é importante e que a formação continuada para todos os professores também é um caminho para melhorar as dificuldades apontadas, bem como a organização do PPP da escola numa perspectiva inclusiva.

A respeito de dois estudos, publicados em 2015 respectivamente: "Práticas pedagógicas inclusivas em sala de aula em diálogo com as salas de recursos 
multifuncionais: atendimento educacional e aprendizagem com sucesso", de Ivanilde Apoluceno de Oliveira e Kátia do Socorro Carvalho Lima; e "O Atendimento Educacional Especializado e as práticas educativas na perspectiva da inclusão na escola Maria Rafols de Breves-PA”, de Ineide Ferreira Baia, são apresentados dois exemplos de ações na perspectiva inclusiva. No primeiro, a ação de uma professora desenvolvida na perspectiva do Desenho Universal da Aprendizagem a fim de garantir a educação inclusiva para todos os alunos de sua classe. Embora o título traga a articulação do professor do AEE com a sala de aula comum, percebe-se na leitura que a agente das ações é a professora regente, que ressalta a importância do professor do AEE, mas que esse diálogo não se estabelece de maneira constante e eficaz.

No entanto, as ações dessa professora atingem o desenvolvimento de todos os seus alunos, pois desenvolve uma prática considerando os perfis de todos eles. O texto deixa claro que essa professora é referência de inclusão em sua escola, modelo admirado, mas não desenvolvido por todos, e, por se tratar de uma ação isolada, as autoras, nas considerações finais do texto, se esquecem de mencionar o professor do AEE, deixando o mérito do sucesso dos alunos apenas a cargo dessa professora.

\section{$\mathrm{O}$ estudo Atendimento Educacional Especializado na rede municipal de} Uberlândia: implantação, organização e desenvolvimento, de Carla Barbosa Alves, publicado em 2015, explora os conceitos da Educação Inclusiva na perspectiva ideal de acontecer, em que a primeira coisa a se compreender é que educação é direito de todos, e a escola possui o dever de garantir permanência e equidade de aprendizagem. A autora destaca que a Escola Inclusiva precisa compreender que todos os seus alunos são diferentes, que os professores são diferentes, mas que todos possuem potencial para aprender, e que o processo de ensino/aprendizagem embasado em modelos tradicionais não mais contempla o público das escolas. Também faz uma profunda reflexão acerca de mudanças de concepção, que exigem transformações que estão arraigadas em nossa formação tanto acadêmica quanto sociocultural.

Ressalta, ainda, a necessidade de modificar o olhar, enxergar o sujeito em seu potencial, destacando, assim, como os demais textos, a relevância da formação para os professores, seja ela inicial ou continuada, devendo a perspectiva inclusiva ser oferecida a todos, pois a complexidade está na necessidade de ressignificar paradigmas, conceitos e valores sociais. Ademais, a autora refere-se à formação inicial e continuada de todos os professores, tanto na perspectiva inclusiva como na da Educação Especial, e ressalta a importância de essa formação considerar tanto o desenvolvimento atitudinal como 
emocional dos professores que precisam lidar com situações diversas e complexas no cotidiano das escolas.

No estudo "Atendimento Educacional Especializado: um diálogo com as práticas da Sala de Recursos Multifuncionais”, de Lidianny Susy de Queiroz Dias e Jhonnys Ferreira do Nascimento, publicado em 2016, retoma-se a importância de discutir educação inclusiva e educação especial, diferenciam-se e conceituam-se as expressões, bem como aponta a necessidade de o professor do AEE, que precisa organizar o serviço na perspectiva inclusiva, receber uma formação adequada. Ao mesmo tempo, a formação de todos os professores precisa ser repensada para que eles estejam preparados para trabalhar na perspectiva da educação inclusiva, e ressalta-se que o modelo praticado pelas escolas não é mais eficiente para o público que a ela pertence. Os referidos autores apontam que a educação especial é um recorte da educação inclusiva, no entanto parece que ela é o carro-chefe para a desconstrução de preconceitos e paradigmas baseados na discriminação e na exclusão. Citam que a SRM, em face de toda essa complexidade, é muitas vezes organizada em perspectiva segregada. Afirmam, ainda, que a inclusão só será possível quando os atos do cotidiano estiverem livres de preconceitos e a aprendizagem considerar o potencial do ser humano em aprender, sem que esteja enquadrado em padrões.

Corroborando os avanços que a educação especial alcançou na história, os estudos "Práticas docentes na classe regular e na Sala de Recursos Multifuncionais: uma reflexão sobre o trabalho colaborativo", de Flavia dos Santos Cota, Carolina Soares Gorne e Flávia Câmara, publicado em 2016, e "A articulação entre as Salas de Recursos Multifuncionais e as salas regulares de ensino: estudo de caso na rede municipal de ensino no município de Jacobina, Bahia”, de Ana Lúcia Oliveira Freitas de Carvalho e Juliana Cristina Salvatori, publicado em 2017, reafirmam que a educação é direito de todos e, analisando o contexto em que o serviço do AEE está sendo organizado, discorrem sobre as dificuldades que observaram e os caminhos em que poderiam ser investidos.

Enaltecem a PNEEPEI, mas criticam o fato de as práticas de efetivação serem superficiais, apontando as dificuldades citadas em textos anteriores, como o pouco ou nenhum diálogo existente entre os professores do AEE e os professores da sala de aula comum, bem como o trabalho segregado desses profissionais, retomando a necessidade de mudanças de paradigmas, pois os professores precisam estar abertos para o desenvolvimento de um trabalho colaborativo. São imperativas ao falar sobre a 
problemática que a formação docente brasileira enfrenta, o que reflete na organização das escolas, e que, tratando-se de inclusão ou, em outras palavras, educação para todos, a escola precisa não apenas garantir acesso, mas também permanência e sucesso dos alunos com equidade e qualidade no processo de ensino/aprendizagem. Consideram importante a existência de uma política em que o professor do AEE e o professor da sala de aula comum consigam estabelecer esse diálogo na escola, e apontam que essa ação também precisa estar articulada no PPP da escola.

Os estudos das autoras Mara Silvia Pasian, Enicéia Gonçalves Mendes e Fabiana Cia, publicados em 2017 e intitulados "Atendimento Educacional Especializado: aspectos da formação do professor" e "Aspectos da organização e funcionamento do Atendimento Educacional Especializado: um estudo em larga escala”, apresentam dois recortes de uma pesquisa realizada em larga escala no Brasil, por meio do Observatório Nacional de Educação Especial (ONEESP), conseguem revelar de maneira mais geral como a organização da Educação Especial tem se dado nas escolas brasileiras e como os protagonistas desse movimento têm se posicionado nesses espaços, os desafios que precisam ser ultrapassados e as ações que já acontecem.

Dentre as ações que já ocorrem, o professor do AEE é responsável por organizar o serviço e a família e a escola sentem-se apoiados por esses profissionais ou, pelo menos, esperam que esse apoio aconteça. Por outro lado, a maioria dos professores do AEE se sente frustrada e solitária na realização do serviço, uma vez que não conseguem estabelecer diálogo com os demais profissionais da escola, que a demanda de serviço exige muito tempo e conhecimento técnico e que a complexidade da educação especial na perspectiva da educação inclusiva precisa acontecer para que o aluno seja promovido em suas habilidades e potencialidades. Eles apontam a formação como fator fundamental para melhorar suas ações, citam que deveria acontecer na perspectiva inclusiva, mas que as especificidades dentro da educação especial também são importantes. Além disso, a existência de outro profissional do AEE nas escolas poderia colaborar para um melhor desempenho do serviço, pois ambos os profissionais discutiriam e organizariam as ações, apoiando-se e estabelecendo conexão com os professores da sala de aula comum e demais segmentos da escola.

O estudo "Atendimento Educacional Especializado em uma perspectiva inclusiva: metodologia em questão”, de Mirlene Ferreira Macedo Damázio, publicado em 2018, apresenta o serviço do AEE transversalizando o todo da escola e, em uma 
perspectiva inclusiva, esquematiza 12 ações que o professor do AEE precisa desenvolver para que o serviço aconteça.

A autora afirma que o professor do AEE deve atuar de maneira flexível e dinâmica, estabelecendo interlocuções e provocando movimentos ao bom trabalho, e sugere ao menos 12 ações a serem realizadas dentro da escola em uma perspectiva inclusiva: (1) acolhimento inicial e elaboração do plano de AEE de acordo com o perfil do aluno; (2) atendimento individual ao aluno ou em subgrupo na SRM; (3) adequação de material pedagógico e tecnologia assistiva (TA); (4) apoio e assessoria ao estudante em sala de aula comum de ensino regular; (5) apoio e assessoria ao professor de apoio de classe comum; (6) apoio e assessoria ao professor de Artes e Educação Física; (7) apoio e assessoria ao professor de apoio escolar; (8) apoio e assessoria aos monitores, cuidadores e/ou estagiários; (9) apoio e assessoria aos gestores (direção e coordenação); (10) apoio e orientação à família; (11) ações intersetoriais - saúde e ação social; (12) elaboração de pareceres e relatórios descritivos analíticos de cunho pedagógico (DAMÁZIO, 2018, p. 48).

Portanto, é importante compreender que a atuação do professor do AEE, na perspectiva inclusiva, não se limita aos atendimentos na SRM em uma visão segregada, mas sim realiza interlocuções com os demais profissionais e setores da escola de forma direta ou indireta em favor do desenvolvimento desses alunos. O serviço deve contemplar transversalidade, complementaridade, interlocuções e conexões, ou seja, oferecer o serviço do AEE em uma visão sistêmica. Discorre a autora que a atuação do AEE precisa transversalizar o serviço no contexto da escola, em um processo dinâmico, dialógico e cheio de movimento, procurando conduzir a equipe escolar e assumir uma postura inclusiva diante do público-alvo da educação especial. Reflete acerca da demanda e ressalta que essas ações devem estar articuladas com as necessidades específicas de cada caso, ou seja, são 12 ações importantes, mas que nem sempre serão necessárias para todos os alunos.

O texto coloca o professor do AEE como agente de mudanças, mas não como ator solitário, e sim com conexões para ajudar na construção de uma educação inclusiva, dado que precisa desenvolver as ações do serviço do AEE nessa perspectiva, mas sua responsabilidade está voltada aos alunos público-alvo da educação especial. A complexidade do serviço também é apontada, bem como a necessidade de repensar as práticas e a importância da formação. Além disso, ressalta que o professor do AEE 
precisa ser corajoso e dinâmico para enfrentar os empecilhos das escolas que ainda hoje não estão prontas para atender a todos os perfis de alunos.

Todavia, não há mais discussão, a escola é lugar de todos, voltando-se, assim, para a modalidade da educação especial. O professor do AEE é responsável por articular a transversalidade do serviço em favor do desenvolvimento e aprendizagem dos alunos, garantindo permanência e sucesso escolar. Ele não está sozinho, mas precisa se posicionar como protagonista.

\section{Considerações finais}

Diante de tudo o que foi exposto, compreendemos que a modalidade da educação especial precisa acontecer na perspectiva da educação inclusiva, pois assim é possível garantir que seus alunos público-alvo tenham oportunidades de qualidade e equidade tanto de aprendizagem como de desenvolvimento. É muito importante ressaltarmos que os paradigmas da inclusão são envolvidos pelo conceito de desenho universal, que a deficiência, os déficits e estereótipos não são o foco das ações inclusivas, e sim o potencial presente em todos os seres humanos, considerando seu perfil e estilos de aprendizagem.

O professor do AEE possui significativa importância e é responsável por fomentar e articular as conexões para que a perspectiva inclusiva se potencialize, mas ele não é responsável por fazer a escola inclusiva.

As práticas encontradas para contribuir com esse profissional na realização de seu serviço, de maneira que o aluno seja atendido em suas especificidades e que as angústias da escola sejam transformadas em motivação, partem da formação do professor, e não apenas do especialista do Atendimento Educacional Especializado, mas para todos os envolvidos na escola; que essa formação precisa estar voltada à perspectiva inclusiva e em paradigmas que considerem o potencial humano, e não um padrão de desenvolvimento.

Ao mesmo tempo, a formação específica para determinadas áreas da educação especial também é elucidada, logo podemos apontar um primeiro caminho que se inicia na formação docente. Também verificamos que a organização das escolas, com metodologias tradicionais, focadas numa visão de público homogêneo, não atende mais a demanda de alunos, e a reformulação de suas práticas é necessária. 
Vimos que a assessoria, o apoio e o diálogo do professor do AEE com o professor da sala de aula comum são descritos nos documentos que norteiam a educação especial, mas que as escolas precisam organizar seus espaços para que essa conexão aconteça de maneira eficiente e constante, e a organização do PPP da escola nessa perspectiva inclusiva, considerando as ações necessárias, é um caminho a ser buscado. É importante ressaltar que o diálogo entre os professores do AEE e os professores da sala de aula comum é a ação mais complexa de acontecer, e todos a compreendem como a mais essencial. O espaço da SRM é apontado como importante, mas fica claro que o serviço do AEE deve ultrapassar suas paredes, e que a educação especial, na perspectiva da educação inclusiva, só acontece quando esse aluno é bem-sucedido e sujeito ativo nos outros ambientes da escola, especialmente dentro da sala de aula comum.

Constatamos também que, mesmo diante de toda a complexidade da educação especial, o professor do AEE é ainda o protagonista da inclusão dos alunos público-alvo da educação especial. Dessa forma, precisamos concordar com Alves (2015) quando nos faz refletir acerca da importância de esse profissional ser assistido tanto nas competências técnicas quanto na emocional.

Assim, oferecendo respostas para minimizar as angústias dos professores do AEE, a transversalidade do serviço é o caminho. Ninguém está sozinho para fazer a inclusão do aluno, todos são responsáveis, e é preciso movimento, mobilização, mudança de paradigmas e crença no potencial do outro.

Portanto, o professor do AEE precisa sair do casulo da SRM, propor-se a trocar conhecimento e experiência com os demais professores da escola, estar e oferecer as ações do AEE onde forem necessárias, pois, como os autores discorreram, para a inclusão do aluno acontecer nem sempre o professor do AEE se restringirá ao atendimento na SRM.

É senso comum a grande complexidade do contexto em que a educação especial está inserida, no entanto é perceptível que os movimentos estão acontecendo e caminhando para mudanças significativas.

As Políticas Públicas em Educação precisam delinear mais estratégias para que as mudanças sejam aceleradas, como formação adequada e diretrizes para as conexões necessárias no ambiente escolar.

Tratando-se de inclusão, é preciso ficar claro que ela não se restringe às pessoas com deficiência, mas a todos, e que também a inclusão não acontece apenas no espaço escolar; ela precisa estar presente em todos os ambientes da sociedade. Para isso, a 
sociedade necessita tornar-se inclusiva e desprender-se de preconceitos arraigados pela extinção e exclusão daqueles que não se enquadram em padrões estabelecidos por grupos que nem sempre são a maioria.

Referindo-se à educação especial, ela é o recorte da educação inclusiva que mais se destaca, afinal está intimamente ligada às capacidades acadêmicas exigidas, e, quando seus alunos são assistidos em suas potencialidades, passam a ser referência de que a inclusão é importante e direito de todos à cidadania.

Embora se destaque a educação especial não é responsável por tornar a escola inclusiva; ela deve acontecer nessa perspectiva e contribuir, mas essa responsabilidade é de todos os agentes que precisam refletir suas práticas e, no cotidiano da escola, buscar ações mais inclusivas que respeitem os perfis e as características de todos.

O professor do AEE é um especialista que, na perspectiva inclusiva, precisa aprofundar-se no desenvolvimento humano, nas práticas do desenho universal e em uma metodologia de ações na perspectiva inclusiva, considerando sempre o potencial humano. O saber específico é importante, mas, antes disso, o saber lidar com o ser humano é mais.

Consideramos que este artigo consegue dialogar com os profissionais do AEE, contextualizando suas maiores angústias, ao mesmo tempo em que ilustramos possíveis ações que possam potencializar o serviço, bem como chamamos a atenção do Estado para a implantação de Políticas Públicas em Educação que garantam um espaço de diálogo e reflexão das práticas inclusivas nas escolas.

\section{REFERÊNCIAS}

ALVES, C. B. Atendimento educacional especializado na rede municipal de

Uberlândia: implantação, organização e desenvolvimento. Universidade Federal de Uberlândia - UFU. Minas Gerais, 2015, 173p. Disponível em:

https://repositorio.ufu.br/bitstream/123456789/14025/1/AtendimentoEducacionalEspeci alizado.pdf. Acesso em: 30 mar. 2018.

ALVES, M. D.; GUARESCHI, T. Compreendendo o Atendimento Educacional Especializado (AEE). In: SILUK, A. C. P. Formação de professores para o atendimento educacional especializado. Santa Maria: Universidade Federal de Santa Maria, 2011. Módulo II, p. 31-60.

BAIA, I. F. O atendimento educacional especializado e as práticas educativas na perspectiva da inclusão na escola Maria Rafols de Breves-PA. Monografias Brasil Escola, 2015. Disponível em:

https://monografias.brasilescola.uol.com.br/imprimir/15414. Acesso em: fev. 2018. 
BATTISTEL, A. L. H. T. Atendimento educacional especializado para pessoas com deficiência física. In: SILUK, A. C. P. Formação de professores para o atendimento educacional especializado. Santa Maria: Universidade Federal de Santa Maria, 2011. Módulo IV, p. 101-136.

BERSCH, R.; MACHADO, R. Tecnologia Assistiva - TA: aplicações na educação. In: SILUK, A. C. P. Formação de professores para o atendimento educacional especializado. Santa Maria: Universidade Federal de Santa Maria, 2011. Módulo III, p. 61-100.

BRASIL, Lei n. ${ }^{\circ}$ 9.394/96, de 20 de dezembro de 1996. Estabelece as diretrizes e bases da educação nacional. Diário Oficial, Brasília, DF, 23 dez. 1996.

BRASIL. Decreto n. ${ }^{\circ} 7.611$, de 17 de novembro de 2011. Dispõe sobre a educação especial, o atendimento educacional especializado e dá outras providências. Diário Oficial, Brasília, DF, 18 nov. 2011. Edição Extra, p. 5.

CANTARELLI, C. S. Grupo de suporte aos pais e apoio pedagógico aos professores da rede e alunos com necessidades educacionais especiais na educação inclusiva. In: MARQUEZINE, M. C.; TANAKA, E. D. O.; BUSTOS, R. M. (Org.). Atendimento educacional especializado. Marília: ABPEE, 2013. p. 87-107.

CARVALHO, A. L. O. F.; SALVATORI, J. C. A articulação entre as salas de recursos multifuncionais e as salas regulares de ensino: estudo de caso na rede municipal de ensino no município de Jacobina, Bahia. In: VI SEMINÁRIO NACIONAL E II SEMINÁRIO INTERNACIONAL POLÍTICAS PÚBLICAS, GESTÃO E PRÁXIS EDUCACIONAL; 24 a 27 de outubro de 2017. Anais... Vitória da Conquista: Universidade Estadual do Sudoeste da Bahia, 2017. p. 205-221. Disponível em: http://periodicos.uesb.br/index.php/semgepraxis/article/view/7211. Acesso em: 26 maio 2018.

COTA, F. S.; GORNE, C. S.; CÂMARA, F. Práticas docentes na classe regular e na Sala de Recursos Multifuncionais: uma reflexão sobre o trabalho colaborativo. In: IV SEMINÁRIO INTERNACIONAL INCLUSÃO EM EDUCAÇÃO: UNIVERSIDADE E PARTICIPAÇÃO; 11 a 13 de maio de 2016. Anais... Rio de Janeiro: Universidade Federal do Rio de Janeiro, 2016. Disponível em:

http://www.lapeade.educacao.ufrj.br/files/Eixo\%205_Formacao\%20Docente_pag\%208 0.pdf. Acesso em: 25 maio 2018.

DAMÁZIO, M. F. M. Atendimento Educacional Especializado em uma perspectiva inclusiva: metodologia em questão. In: FRANCO, M. A. M.; GUERRA, L. B. Práticas pedagógicas em contextos de inclusão: situação de sala de aula. São Paulo: Paco, 2018. p. 45-73.

DIAS, L. S. Q.; NASCIMENTO, J. F. Atendimento Educacional Especializado: um diálogo com as práticas da Sala de Recursos Multifuncionais. In: III CONEDU Congresso Nacional de Educação; 05 a 07 de outubro de 2016. Anais... Natal: Editora Realize, 2016. Disponível em: http://www.editorarealize.com.br/revistas/conedu/trabalhos/TRABALHO_EV056_MD1 _SA7_ID10600_16082016232033.pdf. Acesso em: 21 maio 2018. 
GIL, A. C. Como elaborar projetos de pesquisa. 4. ed. São Paulo: Atlas, 2002.

MENEZES, E. C. P.; CANABARRO, R. C. C.; MUNHOZ, M. A. A escola como um espaço de respeito a diferença. In: SILUK, A. C. P. Formação de professores para o Atendimento Educacional Especializado. Santa Maria: Universidade Federal de Santa Maria, 2011. Módulo V, p. 153-156.

MIRANDA, T. G. Articulação entre o Atendimento Educacional Especializado e o ensino comum: construindo sistemas educacionais inclusivos. Revista Cocar, Belém: Universidade Federal da Bahia, n. 1, p. 81-100, jan.-jun. 2015. Disponível em: https://paginas.uepa.br/seer/index.php/cocar/article/view/614. Acesso em: 15 jun. 2018.

OLIVEIRA, I. A.; LIMA, K. S. C. Práticas pedagógicas inclusivas em sala de aula em diálogo com as salas de recursos multifuncionais: atendimento educacional e aprendizagem com sucesso. Revista Educação e Fronteiras On-line, v. 5, n. 13, p. 149-162, maio-ago. 2015. Disponível em:

http://ojs.ufgd.edu.br/index.php/educacao/article/view/3765. Acesso em: 25 fev. 2018.

PASIAN, M. S.; MENDES, E. G.; CIA, F. Aspectos da organização e funcionamento do Atendimento Educacional Especializado: um estudo em larga escala. Educação em Revista, n. 33, 2017. Portal Scielo. Disponível em:

http://www.scielo.br/pdf/edur/v33/1982-6621-edur-33-e155866.pdf. Acesso em: 19 maio 2018.

PASIAN, M. S.; MENDES, E. G.; CIA, F. Atendimento Educacional Especializado: aspectos da formação do professor. Cadernos de Pesquisa, v. 47, n. 165, p. 964-981, jul.-set. 2017. Portal Scielo. Disponível em: http://www.scielo.br/pdf/cp/v47n165/19805314-cp-47-165-00964.pdf. Acesso em: 19 maio 2018.

\section{PNEEPEI - Política Nacional de Educação Especial na Perspectiva da Educação}

Inclusiva. Brasília: MEC; SEESP, 2008 Disponível em:

http://portal.mec.gov.br/arquivos/pdf/politicaeducespecial.pdf. Acesso em: 16 dez. 2017.

PORTO, P. P.; MARQUEZINE, M. C.; TANAKA, E. D. O. Introdução. In: MARQUEZINE, M. C.; TANAKA, E. D. O.; BUSTO, R. M. (Org.). Atendimento Educacional Especializado. Marília: ABPEE, Marquezine \& Manzini, 2013. p. 7-21.

SILVA, M. J. O.; OLIVEIRA, J. F. P.; AGUIAR, A. L. O. A importância do AEE na mediação do professor na inclusão do aluno com deficiência intelectual na escola. Rio Grande do Norte: Universidade do Estado do Rio Grande do Norte, 2014. Disponível em: http://www.uern.br/controledepaginas/edicao-atual/arquivos/36783_gt4_maria_jusciene_de_oliveira_silva.pdf. Acesso em: 15 mar. 2018.

SILVA, V. C.; FRANKE, M. C. G. C.; MOREIRA, L. C. A rede de apoio permeando ao trabalho do professor no processo de inclusão. In: MARQUEZINE, M. C.; TANAKA, E. D. O.; BUSTOS, R. M. (Org.). Atendimento Educacional Especializado. Marília: ABPEE, 2013. p. 139. 


\section{Como referenciar este artigo}

SOUZA, Mayara Ferreira de; DAMÁZIO, Mirlene Ferreira Macedo. Professor do atendimento educacional especializado na escola comum e as práticas metodológicas inclusivas. Revista on line de Política e Gestão Educacional, Araraquara, v. 23, n. esp. $1, \quad$ p. 897-913, out. 2019. E-ISSN:1519-9029. DOI: https://doi.org/10.22633/rpge.v23iesp.1.12946

Submetido em: 10/05/2019

Revisões requeridas: $14 / 06 / 2019$

Aprovado em: 10/08/2019

Publicado em: 01/10/2019 